\title{
ORPHANATO MUNICIPAL DE BELÉM: ACOLHIMENTO, EDUCAÇÃO E INSTRUÇÃO A MENINAS (1893-1911)'
}

\author{
Antonio Valdir Monteiro Duarte \\ Secretaria de Estado de Educação do Pará, \\ Secretaria Municipal de Educação de Belém, Brasil.
}

\section{$\cos 8$}

\begin{abstract}
Resumo
Este artigo analisa as práticas educativas aplicadas a centenas de meninas que viveram em condição asilar durante a administração de Antonio José de Lemos (1897-1911), período marcado por transformações políticas, econômicas e sociais na capital paraense. Com o objetivo entender as práticas educativas no internato, o estudo revelou que, mesmo se tratando de uma instituição de natureza filantrópica, pelo menos no seu início, os regulamentos, programas e compêndios eram semelhantes aos estabelecidos para as demais escolas públicas. Ficou evidenciado que as disciplinas que envolviam as habilidades práticas, como trabalhos manuais, trabalhos de agulha e as prendas domésticas, tinham prioridade e ocupavam grande parte do tempo das educandas órfãs.

Palavras-chave: meninas órfãs, práticas educativas, Orphanato Municipal de Belém.
\end{abstract}

\section{ORPHANATO MUNICIPAL DE BELÉM: GREETING, EDUCATION AND INSTRUCTION TO GIRLS (1893-1911)}

\section{Abstract}

This article examines the educational practices applied to hundreds of girls who lived in asylum status during the administration of Antonio José de Lemos (1897-1911), in a period marked by major political, economic and social transformations in the capital of Pará. In order to understand, the educational practices at boarding school, the study revealed that, even with a philanthropic nature, at least in its beginning, regulations, programs and textbooks were similar to those established for other public schools. However, it became evident that the subjects involving practical skills like arts and crafts, needlework and household gifts, had priority and occupied much of the time of grassroots orphans.

Key-words: orphan girls, educational practices, Orphanato Municipal de Belém.

\footnotetext{
${ }^{1}$ Este artigo é resultado da tese de doutorado intitulada Órfãs e desvalidas: a formação de meninas no Orphanato Municipal de Belém do Pará (1893-1931), apresentada em agosto de 2013 no Programa de Pós-Graduação em Educação da Universidade Federal de Uberlândia/MG, sob a orientação do prof. dr. Wenceslau Gonçalves Neto. 


\section{ORPHANATO MUNICIPAL DE BELÉM: \\ SALUDO, EDUCACIÓN E INSTRUCCIÓN A LAS CHICAS (1893-1911)}

Resumen

Este artículo examina las prácticas educativas aplicadas a cientos de chicas que vivió en estado de asilo durante la administración de Antonio José de Lemos (1897-1911), período marcado por grandes transformaciones políticas, económicas y sociales en la capital de Pará. Para entender las prácticas educativas en el internado, el estudio reveló que, incluso con carácter filantrópico, al menos en sus inicios, normas, programas y libros de texto eran similares a las establecidas por otras escuelas. Sin embargo, se hizo evidente que los temas que implican habilidades prácticas como artes y manualidades, costura y regalos hogares, tenía prioridad y ocuparon gran parte del tiempo de los huérfanos de la base.

Palabras clave: niñas huérfanas, prácticas educativas, Orphanato Municipal de Belém.

\section{ORPHANATO MUNICIPAL DE BELÉM: SALUTATION, L'EDUCATION ET L'INSTRUCTION AUX FILLES (1893-1911)}

Résumé

Cet article examine les pratiques éducatives appliquées à des centaines de filles qui vivaient dans l'asile au cours de l'administration de Antonio José de Lemos (1897-1911), période marquée par des transformations politiques, économiques et sociales majeures dans la capitale du Pará. Afin de comprendre les pratiques éducatives au pensionnat, l'étude a révélé que, même avec un caractère philanthropique, au moins dans ses débuts, règlements, programmes et manuels scolaires étaient semblables à celles établies pour les autres écoles publiques. Toutefois, il est devenu évident que les sujets impliquant des compétences pratiques comme l'artisanat, travaux d'aiguille et cadeaux ménagers, avait priorité et occupaient une grande partie du temps des orphelins de la base.

Mots-clé: orphelines, pratiques éducatives, Orphanato Municipal de Belém. 


\section{Introdução}

o Pará, o clima de prosperidade aliado à política de imigração dos governos, praticada desde o século 19 com vistas a absorver mão de obra para atuar na agricultura, em especial na economia gomífera, assim como povoar o vasto território paraense, foram elementos importantes para desencadear uma corrida à região por trabalhadores oriundos de vários países e de diferentes partes do Brasil, sobretudo da região nordestina que, de acordo com Sarges (2002a), foi a principal fornecedora de trabalhadores a partir de 1877, momento em que a seca do sertão cearense forçou a saída de milhares de pessoas em busca de melhoria de vida, tendo como um dos destinos a região amazônica.

Foi neste cenário que surgiu, no ano de 1893, uma casa para atender órfãs, denominada Orphelinato Paraense ${ }^{2}$, criada por iniciativa de uma associação formada por importantes famílias da sociedade paraense, chamada Associação Protectora dos Orphãos, instituição filantrópica que tinha como objetivo abrigar meninas órfãs e desvalidas. Porém, poucos anos depois, em virtude das dificuldades enfrentadas pela associação, o governo municipal resolveu assumi-la, transformando-a, a partir de então, num dos mais importantes e polêmicos projetos da municipalidade, confiando à Ordem Religiosa Filhas de Sant'Anna ${ }^{3}$ a sua direção interna.

Sendo assim, a citada instituição passou a ser vista pelos diversos governos, especialmente entre os anos de 1897 a $1911^{4}$, não apenas como um espaço de acolhimento de órfãs, mas como um importante lugar de formação e instrução de centenas de meninas que ali eram internadas e preparadas para "não somente ficar circumscripta ao gracioso papel de ornamentação do lar", mas que compartilhe com o esposo as luctas quotidianas" (Belém, 1904, p. 259).

À medida que o tempo passou, o educandário assumiu novas feições, seja em função das mudanças políticas e sociais, seja no campo de sua administração interna, seja no tocante à regulamentação de seus processos educativos. Para Rizzini (2008), esses espaços destinados ao acolhimento e ao cuidado de meninas órfãs e abandonadas sofreram mudanças de cunho ideológico, especialmente no Brasil, na passagem do século 19 para o 20, quando as práticas em relação à assistência foram incorporadas ao discurso e à ação dos higienistas, provocando o esmorecimento do caráter da misericórdia.

Diante dessas questões é que destaco a história de centenas de meninas que habitaram o Orphanato Municipal de Belém, tendo como marco temporal o ano de 1893, ano de fundação da instituição, e 1911, fim do governo de Antonio Lemos, figura importante na redefinição das políticas no campo da educação na cidade de Belém no período.

\footnotetext{
${ }^{2}$ Esta instituição passou por várias denominações no decorrer dos anos e como forma de identificá-la ao longo do texto optou-se pelo nome de Orphanato Municipal, por ser esta a que mais prevaleceu durante o período definido por este artigo.

3 A referida Ordem, de origem italiana, chegou ao Brasil em outubro de 1884 e assumiu instituições em várias partes do país. No Pará, especificamente na capital, dirigiu várias instituições como: Santa Casa de Misericórdia, Colégio do Amparo, Asilo de Mendicidade e o Orphanato Municipal, desde o ano de sua fundação em 1893 (Revista Jubileu/Papiro da Memória, 2009).

${ }^{4}$ Este período demarca a permanência de Antonio José de Lemos como intendente municipal de Belém.
} Hist. Educ. [Online] Porto Alegre v. 18 n. 43 Maio/ago. 2014 p. $163-182$ 
Assim, este artigo tem como objetivo entender as práticas educativas no interior da instituição e sua relação com o projeto mais amplo de governo da época. Para tal foram utilizados como documentos relatórios administrativos, mensagens governamentais e registros da instituição

\section{Orphanato Municipal: o itinerário de uma instituição para órfãs}

A institucionalização da instrução e da escola pública, gratuita e obrigatória teve, segundo Veiga (2007), sua origem ainda no século 18 e ganhou força no transcorrer do século 19. A ideia seria dar coesão à nova sociedade nacional e civilizar o povo, considerado pelas elites política e intelectual "como indolente, descuidado e atrasado" ( $p$. 132). Para essa mesma autora,

foram inúmeras as falas que retrataram um país indolente, de povo preguiçoso, sem cultura, de hábitos suspeitos, atrasado, indiferente, impulsivo, enfim, uma infinidade de adjetivos desqualificadores. Nesse sentido, a população se tornou objeto da ciência através das práticas dos médicos, higienistas, dos discursos eugênicos, das novas ideias pedagógicas. (2003, p. 56)

Neste sentido, com a Proclamação da República e a busca continuada pela civilidade, os governos dos diversos Estados da federação, assim como dos municípios ${ }^{5}$, aprovaram leis para assegurar e ampliar o direito à instrução de grande parte dos habitantes que vivia na ignorância. No entanto, o modelo de escola e educação que se tentou implantar para as classes populares, no transcorrer da República, em muitos casos, se mantinha fiel a algumas formas herdadas do império brasileiro, como os orfanatos, internatos e asilos.

Segundo Gondra e Schueler (2008), muitos debates foram promovidos no século 19 em relação aos internatos, seja por aqueles que os defendiam, seja por aqueles que os consideravam como um meio de corrupção, excesso e má formação.

Estas instituições de caridade de natureza filantrópica que, num primeiro momento tinham caráter assistencialista, passaram a assumir também a missão de instruir seus internos, oferecendo, no caso das meninas, conhecimentos rudimentares em primeiras letras, práticas manuais e aprendizagens domésticas. Esta estratégia serviu para afastar das ruas muitas crianças que começavam a causar transtornos e má impressão aos moradores dos emergentes centros urbanos, principalmente das principais cidades brasileiras, que se encontravam em processo de formação.

Diante desse cenário, o então Orphelinato Paraense se tornou objeto de várias iniciativas e intervenções por parte da sociedade e das autoridades públicas, sobretudo,

\footnotetext{
${ }^{5}$ Segundo Gonçalves Neto (2012), a maioria dos estudos relacionados à educação brasileira na Primeira República, enfatiza que as iniciativas para a organização da instrução pública foram dos governos estaduais e que houve certa omissão por parte do Estado brasileiro. Esta constatação fica mais evidente nas poucas referências que a ela - a educação pública primária- são feitas na Constituição de 1891. Por outro lado, ainda seriam pouco difundidos os estudos sobre as iniciativas das Câmaras Municipais para a instrução pública na Primeira República.
} 
durante a gestão de Antonio José de $\operatorname{Lemos}^{6}$, que o assumiu como parte de seu ambicioso projeto de modernização e reordenação da capital paraense, obrigando seus sucessores a dar continuidade ao seu propósito de ver o educandário transformado em um importante templo civilizatório.

Inicialmente, apoiado por algumas famílias da alta sociedade local, organizadas em uma entidade denominada Associação Protectora dos Orphãs, o estabelecimento atendia a um pequeno número de meninas desvalidas e recebia, cotidianamente, o apoio e a simpatia da sociedade. No mesmo ano de sua fundação recebeu o apoio da Corporação Artística das Officinas dos Srs. Tavares Cardoso e $\mathrm{C}^{\mathrm{a}}$., importante tipografia da época que lançou, em edição especial, uma revista em homenagem ao Orphelinato, cuja renda obtida com a venda de seus exemplares seria revestida em benefício da instituição.

Três anos após a implantação da instituição, houve uma significativa diminuição no número de sócios efetivos: de um total de 535, no ano de 1893, restavam apenas 102 no ano de 1896 (Belém, 1902). Este fato trouxe muitas dificuldades, considerando-se que no decorrer dos anos, em virtude do crescente número de órfãs acolhidas, as despesas se avolumavam e comprometiam o atendimento na instituição.

Diante deste fato, a instituição teve que sobreviver de outras fontes de receitas, especialmente daquelas oriundas da ação beneficente, como as quermesses, dos trabalhos feitos pelas próprias internas, venda de bens, como joias e terrenos, e de donativos que eram doados à instituição, assim como de pequenos auxílios concedidos esporadicamente pelo governo do Estado.

Em relação ao poder público assumir legalmente instituições dessa natureza, Lobo (2008) destaca que, ainda no século 19, na transição da Monarquia para a República, o Estado Brasileiro ainda não participava diretamente do atendimento às populações pobres, ficando essa atribuição às irmandades ou a associações caritativas. Nesse sentido, a autora conclui que "na verdade, o Estado Brasileiro sempre deixou ao encargo de particulares, a assistência aos necessitados" (Lobo, 2008, p. 325).

No caso do Orphanato Municipal, a realidade mudou a partir de 1900, após ser transformado em uma instituição pública, mediante acordo assinado entre a Associação Protectora dos Orphãos e o então intendente municipal, Antonio Lemos. É neste instante que as transferências de recursos provenientes do erário municipal passam a ser oficiais, tornando o educandário um dos projetos mais importantes da administração de Antonio Lemos.

Pela lei n. 283, de 27 de dezembro de 1900, aprovada pelo Conselho Municipal de Belém, a Intendência foi autorizada a receber, da Associação Protectora dos Orphãos, o Orphanato Municipal. Fruto do sentimento republicano e, acima de tudo, da benevolência de Antonio Lemos, a partir desse momento, o Orphanato se tornou uma das mais

\footnotetext{
${ }^{6}$ Antonio José de Lemos, Maranhense, considerado o grande responsável pela feição de belle époque que se instaurou em Belém, foi intendente municipal durante quatorze anos, tendo sido eleito pela primeira vez em 1887 e renunciado ao mandato, após várias eleições, em junho de 1911. Lemos cursou o Liceu Maranhense, onde estudou Humanidades, tendo como um de seus mestres o filósofo Sotero dos Reis. Em Belém, depois de servir a Companhia de Aprendizes de Marinheiro do Pará, casou-se com dona Ignez que desempenhou obedientemente o papel hierárquico a que lhe cabia enquanto esposa e mãe. Essa imagem de dona Ignez, enquanto esposa recatada, a "protetora do lar", representava o papel que o positivismo, inspirador da República brasileira, reforçou na figura da mulher; ela seria a responsável pela reprodução dos valores morais da humanidade (Sarges, 2002b).
} 
"sympáticas e civilisadoras" (Belém, 1902, p. 241) instituições municipais, notadamente na primeira década do século 20

Esta iniciativa política, tomada em relação à instituição, não se resumiu apenas na ideia de garantir abrigo ou cuidado às meninas desamparadas e desvalidas, ela se alinhou ao projeto reformista iniciado na capital paraense de civilizar a população. Para Yazbeck (2012), o pensamento republicano reiterava a necessidade de se modernizar o país, tendo a escola como um dos principais caminhos para formar o cidadão e torná-lo apto a participar da ordem republicana liberal.

Foi trilhando este caminho que a municipalidade assumiu o Orphanato, nos termos da lei n. 283, aprovada pelo Conselho Municipal:

Art. $1^{\circ}$ - Fica o Intendente auctorisado a receber da Associação Protectora do Orphãos o instituto de caridade denominado "Orphelinato Paraense", que passará a ser mantido e custeado pelo Governo Municipal. $\S 1^{\circ}$ - O Intendente regulamentará immediatamente os fins do instituto, numero maximo de orphãs que poderão ser nelleadmittidas, sua educação e instrucção, bem como a administração interna do estabelecimento, marcando o pessoal necessario para todos os trabalhos enumerados. $\S 2^{\circ}$

- A regulamentação de que trata o $\S$ anterior entrará em execução provisoria, até que o Conselho, a cuja aprovação será immediatamente submetida, resolva definitivamente. Art. $2^{\circ}$ - O Intendente receberá da directoria da Associação Protectora dos Orphãosos bens, moveis, immoveis e dinheiro ou titulos que representem o patrimonio do Orphelinato e das orphãs neste asyladas, afim de que a Municipalidade possa responsabilisar-se pelas dividas relativas ao mencionado instituto, tudo mediante as cautellas previstas em direito. Art. $3^{\circ}$ - Recebido o Orphelinato, o Intendente procederá aos meios de localisal-o convenientemente, de modo mais economicopossivel, tendo em vista a hygiene e conforto exigidos em estabelecimentos de tal ordem. Art. $4^{\circ}$ Revogam-se as disposições em contrario. Mando, portanto, a todos os habitantes do Municipio que a cumpram e façam cumprir tão inteiramente como nella se contém. Dada e passada nesta cidade de Belém, aos 27 de Dezembro de 1900. (Belém, 1900, p. 76-77)

Certamente que para o gestor municipal essa iniciativa representou uma importante conquista para o projeto de reestruturação e modernização da cidade, pois, amparar uma instituição desta natureza, além de ser uma maneira de racionalizar o espaço público, tornando-o mais adequado, inclusive do ponto de vista da ciência higiênica, somava pontos a seu favor em relação às suas pretensões políticas enquanto liderança do Partido Republicano e potencial candidato ao cargo de governador do Estado do Pará.

No momento da assinatura do contrato de transferência, a direção do Orphanato, representada por José H. Cordeiro de Castro, Manoel Ignacio da Cunha e Euclydes Faria, entregou ao intendente municipal um relatório datado de 17 de abril de 1900, contendo algumas informações das atividades desenvolvidas na instituição, desde sua fundação: títulos patrimoniais, balanço financeiro e a relação nominal das asiladas existentes na instituição.

De acordo com os dados do relatório, confirmados no livro de matrícula da instituição, moravam na instituição 46 meninas órfãs, de diferentes naturalidades e nacionalidades, como se pode perceber no quadro a seguir. 


\section{Quadro 1}

Relação da origem e do número de meninas internas existentes no Orphelinato Paraense no ano de 1900.

\begin{tabular}{|c|c|c|c|}
\hline Brasileiras & Quantidade & Estrangeiras & Quantidade \\
\hline Paraenses & 32 & Portuguesas & 2 \\
\hline Cearenses & 3 & Hespanholas & 2 \\
\hline Amazonenses & 2 & Peruanas & 1 \\
\hline Pernambucana & 1 & Americana do Norte & \\
\hline Fluminense & 1 & & 6 \\
\hline Maranhense & 1 & & \\
\hline Total & 40 & Total & \\
\hline
\end{tabular}

Fonte: Relatório da intendência Municipal de Belém, 1902.

Apesar do número reduzido de meninas a administração acreditava que a instituição poderia rapidamente prosperar e ampliar sua capacidade de atendimento, com mais qualidade e competência. No relatório publicado no ano de 1902, enviado aos vogais do Conselho Municipal de Belém, Antonio Lemos descreveu seus primeiros cinco anos à frente da administração e enfatizou as condições em que se encontrava o internato: "Como participei ao Conselho opportunamente, encontrei nas peores condições o predio onde estava installado o Orphelinato: a carencia de recursos não permittira á Associação Protectora dos Orphãos remediar tão sérios inconvenientes" (Belém, 1902, p. 245).

No entanto, o gestor municipal soube reconhecer os méritos da Associação Protectora dos Orphãos no cumprimento de seu papel filantrópico junto aos mais necessitados, apesar das inúmeras dificuldades enfrentadas:

N'essa ocasião, tive mais uma vez o grato ensejo de externar merecidos louvores á directoria da Protectora dos Orphãos, e mais especialmente á actividade e dedicação do sr.dr. Cordeiro de Castro, o infatigável paladino d'aquelle instituto, que a elle, sobretudo, deve sete anos de existencia em lucta de todos os momentos com as mais sérias difficuldades. (Belém, 1902, p. 244)

Diante dos grandes investimentos com as diversas obras de modernização que se processavam na cidade, especialmente no âmbito do saneamento, Antonio Lemos não se furtou em recorrer aos conselheiros municipais para tentar garantir mais recursos para a instituição. No entanto, para colocar em prática o novo projeto, seriam necessários recursos para melhorar as instalações ou alugar um novo edifício, uma vez que o proprietário do atual, ao ser consultado, deixou transparecer que aumentaria substancialmente o valor do aluguel.

O interesse público em assumir e garantir recursos para uma instituição surgida sob os cânones da caridade e da filantropia, na passagem do século 19 para o século 20 no Brasil, vem na esteira das grandes premissas republicanas de reformatação da sociedade e do cidadão, momento em que leis e políticas de assistência a crianças e adolescentes tomam novas configurações. 
Segundo Rizzini (2009), durante o Brasil Império a preocupação com a infância era permeada por ações de recolhimento de crianças órfãs e expostas e se pautava na ideologia cristã, de caráter assistencialista, lideradas pela iniciativa privada de cunho religioso e caritativo.

Assim, imbuído do espírito republicano e modernizador, o intendente municipal convenceu os conselheiros e conseguiu alugar um novo prédio, a custos mais baixos e com maior capacidade para atender aos inúmeros pedidos de internação de meninas órfãs oriundos de seus correligionários da capital e de outras regiões do Estado:

Devidamente auctorizado pelo art. $3^{\circ}$ da citada Lei $n^{\circ} 283$, recebido o Orphelinato, procedi aos meios de localizar convenientemente, do modo mais economicopossivel, tendo em vista a hygiene e bem-estar exigidos em estabelecimentos de tal ordem. (Belém, 1902, p. 245)

De acordo com o intendente, apesar das boas condições do prédio, haveria necessidade de realizar várias reformas e adaptações para funcionarem como refeitório, cozinha, depósito e espaço para arrecadação ${ }^{7}$. Segundo o gestor municipal, mesmo ainda não sendo o local ideal para a acomodação e formação das órfãs, "o edifício, dotado de ar e luz em quantidade, extremamente asseiado" (Belém, 1902, p. 246), atendia aos objetivos mínimos de uma instituição asilar, com finalidades civilizatórias.

Em vista das melhores condições do estabelecimento e das campanhas de divulgação, os pedidos para matrícula se intensificaram, obrigando o executivo municipal a estabelecer normas para o ingresso de novas órfãs na instituição. Era intenso o fluxo de meninas que chegavam à capital, acompanhadas ou não de suas famílias, em decorrência dos programas de imigração, forçando a direção interna da instituição e o poder público a aceitar novas matrículas. Certamente que estes fatores alimentaram o desejo do intendente municipal de construir um moderno edifício, mais aparelhado e melhor localizado para atender a essa parcela da população.

Logo após a inauguração do novo Orphanato à avenida São Jeronymo, o número de internas rapidamente passou de 46 para 56 órfãs, número ainda aceitável, considerando os "53 leitos de ferro, arrumados em pelotão, com pequenos intervalos, por onde mal se passa de lado" (Pará, 1902, p. 60).

O entusiasmo de Lemos pelo então Orphanato era tamanha que em todos os relatórios enviados ao Conselho Municipal de Belém havia uma sessão especial, em que prestava conta do cotidiano da instituição, assim como do início das obras do novo edifício na vila de Santa Izabel, distrito pertencente ao município de Belém.

Cumprindo o que havia sido estabelecido no contrato de transferência do Orphanato o executivo municipal publicou, no mês de dezembro do ano de 1903, a lei n. 370 , pela qual reorganizou-se a instituição, principalmente no que se referia à instrução, à administração interna, ao custeio e à nova denominação do orphanato:

\footnotetext{
7 Apesar de não estar evidenciada, em nenhum dos documentos analisados, a finalidade do espaço de arrecadação, acredita-se que nele eram recebidas e guardadas as doações e donativos ofertados pela sociedade, assim como o pagamento pelos trabalhos manuais confeccionados pelas órfãs.
} 
Art. $1^{\circ}$ - Fica o Intendente auctorizado a reorganizar, como indica em seu relatório de I do corrente, o Orphelinato Municipal, que passa a ser denominado, desde já, Orphanato Municipal de Belém, imprimindo-lhe novos moldes, no que concerne á educação e instrução das orphãs. Art. $2^{\circ}$ - Para o fim de que trata o artigo anterior, fará o Intendente acquisição de terras de campos sufficientes, servidas por aguas abundantes, nas quaes levantará os commodos precisos, não só á residencia e diversos mesteres das orfhãs e pessoal administrativo, como também aos variados serviços em que têm de ser preparadas e empregadas as mesmas orphãs. Art. $3^{\circ}$ Além da instrucçãoletterariainsdispensavel e rudimentos da agronomia, as orphãs serão educadas em prendas domesticas até bordado a branco e nos diversos trabalhos agrarios a que são destinadas, sem prejuízo da educação physica que devem ter. $\S$ unico - também será ministrado ás orphãs o ensino de musica, quanto necessário para o canto coral. Art. $4^{\circ}$ A administração do orphanato será da escolha do Intendente, o qual incumbirá de similhante missão pessoas de reconhecida aptidão e moralidade, preferindo religiosas que estejam dispostas e preparadas para tal mistér. Art. $5^{\circ}$ - O Intendente regulamentará a presente lei, submettendo o regulamento que promulgar á approvação do Conselho, ssemprejuizo de sua immediata execução. Art. $6^{\circ}$ - Todas as despesas com o Orphanato correrão por conta do credito que fôr votado nos orçamentos annuaes para - custeio d'essa instituição, podendo ser augmentado, conforme as necessidades da installacão e desenvolvimento do estabelecimento. Art. $7^{\circ}$ - Revogam-se as disposições em contrario. (Belém, 1903, p. 258)

No artigo $2^{\circ}$ observamos que a possível construção do novo educandário na vila de Santa Izabel denota o interesse em reorganizar o espaço urbano, afastando instituições públicas como hospitais, abrigos, asilos e orfanatos do centro da capital, como forma de prevenção e estabelecimento de uma ordem pautada na medicina higiênica.

Nesse ponto, José Veríssimo, ao defender os princípios da higiene em relatório ${ }^{8}$ enviado ao governo do Estado do Pará, no curto período em que ocupou o cargo de diretor geral da instrução pública ${ }^{9}$, foi bastante enfático ao tratar da questão da higiene em uma instituição pública.

Num dos tópicos do relatório são descritas as condições apresentadas no Collegio do Amparo, instituição congênere ao Orphanato Municipal sob a responsabilidade do governo do Estado. Na oportunidade, Veríssimo criticou a maneira como as órfãs eram tratadas na instituição e demonstrou insatisfação com o modelo de atendimento público. Fez, ainda, o seguinte comentário relacionado à estrutura física considerada por ele ideal, segundo padrão europeu:

Em 1882, o Ministro da Instrucção Publica em França, instituio uma commissão de hygiene escolar, da qual faziam parte o eminente pedagogista Sr. Gréard, o diretor do Museu Pedagogico, Sr. Berger, o famoso hygienista Bouchardat, e muitos outros, medicos, hygienistas,

${ }^{8}$ O relatório intitulado A Instrucção Publica, de 1890, enviado ao Governador do Estado, dr. Justo Leite Chermont, impresso em Belém pela Typ. De Tavares Cardoso e Comp., trata da instrução pública em geral, destacando os vários setores da Diretoria Geral da Instrução, como: Direcção e administração, Inspecção e fiscalisação do ensino, Ensino primario, Escola Normal, Ensino Secundario, Ensino Profissional e Technico, Ensino Particular.

9 José Veríssimo assume o cargo durante o governo de Justo Leite Chermont, entre os anos de 1890 e 1891. (Pará, 1891). 
pedagogos, membros do ensino, engenheiros, architectos. O Relatorio geral d'essa grande comissão, redigido pelo Dr. Javal, e resumidos os relatórios das comissões parciaes em que Ella se subdividio traz, entre muitas outras, as seguintes conclusões: os internatos devem ser, tanto quanto possível colocados fóra das cidades. Nas salas de classe, estudos e dormitorios, é necessaria uma renovação de ar de 15 metros cubicos pelo menos por alumno e por hora. Nos dormitorios deve-se requerer 25 metros cubicos de ar por alumno e por hora, não sendo nunca inferior a cubagem de 16 metros. A superficie dos refeitorios será calculada no minimo á razão de 1 metro por alumno. As materias porosas devem ser evitadas na construcção de um refeitorio; o melhor é empregar exclusivamente para o solo, Lages ou mosaicos, para as mesas, a pedra, o marmore ou o vidro, para as paredes a escariola (stuc) e os azulejos. (Ministère de l'instr. Pub. - hygiène des écoles primaires, etc. Paris. Imprimerie Nationale, 1884). (Pará, 1891, p. 171)

Para Veríssimo, estas deveriam ser as normas, do ponto de vista arquitetônico, que deveriam ser seguidas, tendo como exemplo o modelo francês. Para ele, diante das atuais circunstâncias encontradas no Colégio do Amparo, nenhuma forma de instrução poderia prosperar e que, mesmo a pretexto de qualquer ação de caridade, seria um crime manter meninas em situações tão degradantes.

Ainda de acordo com o diretor da instrução pública, face à realidade encontrada no então Colégio, o Estado deveria dispor de espaços mais condizentes com o ambiente republicano, pois, naquela situação não haveria nenhuma possibilidade de se praticar qualquer forma de educação e, muito menos, de instrução:

Comprehenderiamos talvez, então, que encerrar alhi duzentas meninas, sem espaço, é, a pretexto de beneficencia e caridade, um crime; é conscientemente debilital-as, encerral-as, anemical-as e longe de educarmos e prepararmos para as durezas da vida domestica que naturalmente espera as raparigas pobres, desvalidas, sem familia algumas, para os trabalhos do lar do operario, do artesão, do jornaleiro, do modesto funccionario, mulheres sans, vigorosas e robustas, entregamol-as á sociedade enfezadas, estioladas, hystericas, inuteis. (Pará, 1891, p. 172)

Assim, diante do clima de transformação por que passava Brasil e, particularmente, a capital paraense, inspirado pelos modelos europeus de sociedade, escola e educação, os republicanos, liderados no Estado pelo então intendente municipal, não mediam esforços para projetar e manter instituições educativas como o Orphanato Municipal que, àquela altura, representava a construção de condições que permitissem o pretendido progresso, além de ser o meio de se chegar à condição de cidade, Estado e nação civilizados.

\section{As práticas educativas aplicadas às órfãs}

A partir da fundação do Orphelinato Paraense, no ano de 1893, resultante da iniciativa de algumas famílias da elite paraense, preocupada com o súbito crescimento populacional e, consequentemente, pelo surgimento de pessoas indesejadas e desamparadas - como velhos, mendigos, órfãos - que não contavam com nenhuma forma de subsistência, foi se delineando aquele que seria um dos mais importantes projetos de cunho caritativo, pelo menos durante as primeiras décadas do século seguinte. 
Desta forma, o investimento no atendimento das órfãs desamparadas seria uma das alternativas encontrada pelo executivo municipal para minimizar os problemas sociais. No entanto, em virtude do oneroso modelo de assistência e instrução exigidas por este tipo de instituição, haveria necessidade do poder público, em algum momento, dispor de uma estrutura física, material e pedagógica para garantir, não só um saudável ambiente para moradia das asiladas, como consistente formação doméstica e alguma instrução literária e em primeiras letras.

A preocupação precípua das entidades associativas e das autoridades públicas em relação às instituições dessa natureza estava voltada para o cuidado e o amparo, porém, isto seria insuficiente diante dos avanços impostos pelo progresso e também em virtude das demandas surgidas no interior da instituição, que cada vez mais exigia investimentos que viessem garantir a qualificação das internas.

No que se refere à instrução das órfãs, ao final do primeiro ano de instalação da instituição, a 15 de dezembro de 1893, diante de uma comissão formada por senhoras da alta sociedade que faziam parte da Associação Protectora dos Orfãos, tendo na presidência Amália Rosalina de Faria, foram realizados exames para verificar "o grau de aplicação nos trabalhos manuais" e também avaliar condutas como "docilidade" e "obediência" em vinte educandas (Belém, 1902).

Este procedimento revela que, no primeiro ano de instalação da instituição e mesmo antes de ser transferida para a municipalidade em 1901, as órfãs já eram submetidas a uma avaliação. Certamente que nesses primeiros anos, 1893-1900, todas as orientações pedagógicas eram estabelecidas pela própria associação, mesmo que os poucos documentos do período não deem muitas pistas a esse respeito.

Apesar das peculiaridades e das especificidades de funcionamento do Orphanato, o processo educativo e instrucional das internas estava pautado nas regulamentações definidas, tanto pelo governo estadual, quanto pelo municipal.

A lei municipal n. 370, de dezembro de 1903, pode ser considerada, do ponto de vista oficial, o primeiro instrumento regulamentador da instituição desde sua fundação no ano de 1893. Composta por sete artigos e um parágrafo, a referida lei que autoriza o intendente a reorganizar o Orphanato Municipal, faz referência de forma mais específica às questões educativas em seu terceiro parágrafo:

Art. $3^{\circ}$ - Além da Instrução litteraria indispensavel e rudimentos de agronomia, as órfhãs serão educadas em prendas domesticas até bordado a branco e nos diversos trabalhos agrarios a que são destinadas, sem prejuizo da educação physicaque devem ter. § unico - Também será ministrado ás orphãs o ensino de musica, quanto necessario para o canto coral. (Belém, 1904, p. 258)

É interessante observar que mesmo o Orphanato estando localizado em uma área urbana, as orientações legais indicavam, já naquele momento, que os conhecimentos transmitidos às órfãs teriam que versar sobre agronomia e trabalhos agrários. Essa intenção talvez demonstre o interesse da administração municipal em transferir a instituição para a zona rural, o que irá correr somente no ano de 1928.

A implantação deste tipo de conhecimento não foi possível, contudo, antes de 1928, em virtude de não haver condições físicas e materiais no prédio em que funcionava o 
Orphanato, frustrando, assim, a proposta de transformá-lo de imediato em um instituto técnico-profissional, segundo o que sinalizava o artigo $3^{\circ}$ da lei.

Em relação aos níveis de escolaridade e à faixa etária, podemos observar, inicialmente, que nos dados enviados por Tita Armelline, diretora do Orphanato, à Intendência Municipal, constam que até setembro de 1903 haviam 88 educandas regularmente matriculadas e que estas estavam organizadas em várias classes, como está demonstrado na tabela a seguir.

Tabela 1

Educandas matriculadas nas quatro classes por faixa etária no ano 1903

\begin{tabular}{|c|c|c|}
\hline Nível & $\mathrm{N}^{\circ}$ de educandas & Faixa etária \\
\hline $1^{\mathrm{a}}$ classe & 12 & 3 a 11 anos \\
\hline $2^{\text {a }}$ classe & 34 & 4 a 18 anos \\
\hline $3^{\text {a }}$ classe & 18 & 9 a 18 anos \\
\hline $4^{\text {a }}$ classe & 24 & 7 a 18 anos \\
\hline Total & 88 & 3 a 18 anos \\
\hline
\end{tabular}

Fonte: Elaborada a partir do Relatório da Intendência Municipal de Belém, 1904.

É possível observar, a partir destes dados, que era comum a presença de educandas com idades diferentes em uma mesma classe, não sendo, essas diferenças, empecilho para a formação das turmas. Ao que tudo indica, a passagem para a classe seguinte dependia do desempenho particular de cada aluna, não havendo necessidade de uma padronização em que a faixa-etária fosse a principal referência.

Ao ser aceita e matriculada na instituição, a interna era submetida a uma avaliação prévia, aplicada por uma comissão examinadora para se verificar o nível de conhecimento pedagógico para, posteriormente, ser incluída em uma das quatro classes/níveis que compunham o Curso Elementar do Ensino Primário. É importante destacar que não encontramos indícios que apontem para a existência do Curso Complementar ${ }^{10}$ nos primeiros anos da instituição e nem uma data precisa de sua instalação.

Outra questão que merece ser destacada nos documentos analisados é que em muitos casos não se respeitava uma data ou período e nem idade específicos para o ingresso na instituição, mesmo havendo algumas orientações a esse respeito ${ }^{11}$. Esses fatores podem ter contribuído para a disparidade de faixa-etária nas classes que compunham o ensino primário da instituição.

Este fato demonstra que a necessidade de acolher a qualquer tempo a órfã era o critério principal e, em decorrência disso, sua inclusão nas classes, na maioria das vezes, se fazia necessária.

Segundo Gondra (2007), na França, a entrada de crianças nos internatos seguia uma orientação dos médicos higienistas, acontecendo em alguns casos no período do

${ }^{10} \mathrm{O}$ Curso Complementar representava a etapa seguinte ao Elementar e era composto por duas classes ou níveis.

${ }^{11}$ Essas orientações são mencionadas por Augusto Olympio em artigo denominado Ensino à orphãs, publicado na revista $A$ Escola, organizada pelo governo do Estado, ano de 1900, elas determinam que para ser aceita a matrícula, seria necessário que a órfã tivesse no mínimo sete anos de idade e não mais que doze. 
aleitamento. As mães não hesitavam em confiar o cuidado de seus filhos a outras mulheres ou às mercenárias. Para este autor, "isso implica reconhecer a existência de internatos variados, havendo aqueles que recebiam crianças muito pequenas" (Gondra, 2007 , p. 229), e outros, como no caso do Orphanato Municipal, que aceitava crianças de idades variadas e que, por consequência disto, tinha também classes variadas.

Grande parte do tempo das órfãs era para a realização dos trabalhos manuais, em que eram confeccionados artigos para exposição e venda em quermesses e eventos beneficentes. Apesar de ser assegurado em lei que a interna deveria ter uma formação literária indispensável e rudimentos de agronomia, para fazer frente às novas formas de produção, a representação da mulher e o modelo de sua formação e, especialmente, daquelas que viviam em condição asilar, ainda estavam ancorados na aprendizagem das práticas manuais e prendas domésticas ${ }^{12}$, ainda que já se previsse para o futuro da instituição, de acordo com o pensamento reformador da época, uma formação pautada nos conhecimentos técnico-agrícolas, experimentados, inclusive, com grande sucesso, em países europeus.

\section{O ensino de primeiras letras, a formação literária e os trabalhos manuais}

A formação pedagógica das internas que viveram no Orphanato Municipal de Belém, desde sua fundação em 1893 e, especialmente, a partir da primeira reforma da instrução do Estado em 1903, esteve pautada pelas transformações ocorridas nos projetos educativos, tanto do Município, quanto do Estado.

$\mathrm{Na}$ lei estadual n. 1.190, de 17 de fevereiro de 1903, que reorganizou o Regulamento Geral do Ensino Primário do Estado, no artigo $2^{\circ}$, $\S 5^{\circ}$, estava determinado que fossem definidos os programas de ensino primário no Estado do Pará. Diante disso, no dia 19 de fevereiro deste mesmo ano, os programas de ensino foram aprovados pelo decreto lei n. 1.191. De acordo com este decreto, a finalidade do Curso Elementar era que os alunos pudessem "ler corretamente e escrever com acerto" e que o ensino da escrita deveria começar com a aprendizagem da leitura.

Segundo Vidal e Gvirtz (1998), este procedimento pedagógico se pautava no método sucessivo aplicado pelos professores em grande parte das escolas isoladas e que, "apesar de, desde 1840, ser indicado o método simultâneo, o ensino era seriado: as disciplinas sucediam-se umas às outras. Assim, primeiro a criança aprendia a ler o $A B C$ e as sílabas, para só então conhecer a escrita" (p. 16).

No Curso Complementar do Ensino Primário, dividido em dois anos, havia uma ampliação das disciplinas e das matérias, sendo que o ensino de leitura, de escrita e de Aritmética tinha, assim como no nível elementar, um lugar de destaque. Ao lado destes componentes curriculares, o ensino de Português, Geometria, Geografia e História completavam as disciplinas do programa, tanto do primeiro, quanto do segundo ano do Curso Complementar.

\footnotetext{
${ }^{12}$ De acordo com Nagle (1976), se por um lado a educação profissional feminina no início do século 20 , em São Paulo, tinha como pressupostos garantir conhecimentos e proporcionar a prática de artes e ofícios e a capacidade técnica nas pequenas indústrias, por outro, tinha também como propósitos contribuir para a independência da mulher e atraí-la para os trabalhos manuais e ocupações domésticas, assim como, prepará-la para a função de dona de casa.
} 
O Método Intuitivo ou Lições de Coisas era tido como procedimento pedagógico de destaque nas escolas públicas de todo o Estado, sendo afirmados e difundidos pelos estudos de Rui Barbosa, que os considerava como os mais apropriados para o aprendizado das crianças e adolescentes, uma vez que se baseava nos sentidos, na observação e na reflexão. Este método tinha como finalidade "cultivar na criança as faculdades perceptivas, assimilar-lhe ao espírito a arte de observar, adestrá-la ao encontrar, diante de cada objeto, a palavra apropriada, em achar diante de cada palavra, na inteligência, a concepção da realidade correspondente" (Nascimento, 1997, p. 11).

Ainda de acordo com Nascimento, as reflexões lançadas por Rui Barbosa em seus pareceres acerca da instrução primária e, especificamente, do método intuitivo, estavam fundamentadas em pensadores como Bacon, Comenius e Pestalozzi. A autora observa também que Rui Barbosa, ao se utilizar das palavras de Comenius, faz a seguinte declaração:

É pela intuição real e não por descrições verbais que o ensino deve começar. Dessa intuição dimana o conhecimento. Não são as sobras das coisas mesmas, que atuam na inteligência, nas faculdades imaginativas, e, portanto, devem estar submetidas sempre à atenção da mocidade. Palavras, sem o conhecimento das coisas, são palavras vãs. (1997, p. 11)

Segundo Machado (2005), para Rui Barbosa, tanto o método intuitivo, quanto as lições de coisas seriam "a cura para três séculos de um ensino abstrato e morto, baseado na repetição" (p. 99).

Na reforma da instrução de 1910 um dos elementos que merece destaque diz respeito à implantação dos conteúdos da gymnastica escolar e dos trabalhos manuaes e de agulha (Pará, 1910).

No que se refere aos trabalhos manuais e de agulha, era uma das práticas mais comuns no interior de instituições que abrigavam meninas desvalidas desde o século 19 , tendo em vista as grandes exposições, em que eram vendidas as peças confeccionadas pelas internas. Esta prática primava pelo desenvolvimento de habilidades para a vida doméstica, sendo este um dos objetivos principais da formação das órfãs abrigadas.

Em relação à cultura material escolar, Souza (2007), observa que o surgimento de um moderno e diversificado mobiliário escolar e de novos materiais de ensino se proliferou para dar visibilidade e sustentação aos novos processos pedagógicos que seriam disseminados nas instituições educativas, projetadas no final do século 19 no Brasil.

Nesse sentido, podemos concluir que, pelo menos no Pará, a maioria dos ambientes asilares para meninas internas se constituíam em espaços privilegiados de recursos pedagógicos, acompanhando as transformações ocorridas neste setor no alvorecer do regimente republicano.

Consideramos importante destacar que os regulamentos que orientavam a formação das meninas que viviam no Orphanato Municipal de Belém, mesmo estando sob a égide da legislação do ensino primário do Município e do Estado, não se distanciavam da sua principal missão que era a de formar donas de casa prendadas e com conhecimento sobre as práticas domésticas. 
Os equipamentos pedagógicos utilizados para a aprendizagem na instituição eram o diferencial em relação às demais escolas municipais, tendo em vista que o processo de aprendizagem, preconizado pelos trabalhos manuais e domésticos, era condição essencial não só para formar, mas também dar condições para que as órfãs viessem a desenvolver uma profissão no futuro.

Neste sentido, Souza (2007), ao relacionar estes aspectos aos contextos vivenciados pelas escolas ao longo dos tempos, observa que "embora tomados como quase sempre como um pressuposto natural, os artefatos materiais vinculam concepções pedagógicas, saberes, práticas e dimensões simbólicas do universo educacional constituindo um aspecto significativo da cultura escolar" (p. 169).

Antonio Lemos, em suas inesperadas visitas ao Orphanato, não deixava de elogiar a qualidade dos trabalhos produzidos diariamente pelas internas. Sua satisfação era mais evidenciada quando aconteciam as festas beneficentes, momentos em que se faziam presentes as damas e cavalheiros, tornando estes eventos grandes acontecimentos da sociedade paraense:

São, com effeito, incontaveis os primores de prendas que têm sahido do Orfanato Municipal, attestando galhardamente o cuidado e o bom gosto que presidem ás iniciativas d'essa modelar casa de educação feminina. Por occasião da recente Kermesse no Bosque, em favor da Capella do Sagrado Coração de Jesus, a cabana Cecy expos uma grande e custosa colleção de bordados de gostos e feitios vários, constituíram uma das notas chics d'essa movimentada feira de caridade. Almofadões, pannos de mesa, applicações de aquarella e oleo, obras de sêda e setim, bordados a branco, a matiz, a sêda frouxa, em baixo e alto relêvo - e infindaveis outras obras, tudo tem sahido do Orfanato, sempre dando ensejo a encomios, não só pela meticulosa delicadeza do acabamento, como pela distincção e propriedade das combinações dos coloridos e desenhos. (Belém, 1905, p. 269)

Em fevereiro de 1906 foi realizada uma feira para exposição de várias peças confeccionadas durante as aulas de agulha e prendas domésticas. A partir deste ano o evento ganhou importância e passou a ser realizado anualmente, sendo considerado um importante momento, não só de culminância pedagógica, mas financeiro e político, uma vez que contribuía para o orçamento do estabelecimento e para o reconhecimento e a projeção da figura do então intendente municipal no cenário paraense.

Mesmo o que poderia ser um simples evento, como uma exposição de trabalhos manuais, se transformava em acontecimento de cunho político e social, tendo em vista o forte apelo social demandado por essa forma de ação caritativa, como podemos observar nas descrições a seguir:

A abertura da modesta feira, em que fôram expostos trabalhos delicadissimos, reveladores do cuidadoso esmero com que é ministrada a educação das creanças confiadas á guarda do Municipio - resultou uma festa das mais encantadoras de quantas tenho presenceado. Após a missa, a que assistiu o sr.dr. Augusto Montenegro, governador do Estado, com sua virtuosa esposa, além de grande numero de cavalheiros e senhoras da nossa sociedade, declarei aberta a exposição, que foi logo visitada por centenares de pessôas. Foi a exposição installada n'uma 
grande sala á direita do edificio, achando-se os objetos methodicamente arrumados ou em cavalletes, ou em banquetas, ou sobre improvizadas prateleiras, com os preços marcados em cada uma. Quasi todas as pessôas presentes adquiriram trabalhos, de sorte que, ao ser elle encerrado, no dia 4, pouco restava a vender. Só esta circumstancia, para a qual chamo especialmente a vossa attenção, basta afim de deixar bem patente a perfeição dos trabalhos das meninas do Orfanato. (BELÉM, 1907, p. 220)

As peças confeccionadas pelas educandas durante a aulas de prendas eram meticulosamente acompanhadas pelas professoras regentes e pelas religiosas da Ordem Filhas de Sant'Anna, que assumiam também esta função. Apesar de haver constantes mudanças das religiosas na instituição, havia uma continuidade das aulas e dos trabalhos produzidos pelas educandas.

As religiosas exerciam as mais diferentes funções junto à instituição, porém, todas elas atuavam naquelas ligadas à instrução literária, às aprendizagens domésticas e, sobretudo, no ensino dos trabalhos manuais, sendo comum a contratação de senhoras de fino trato para lecionar Primeiras Letras e Prendas na instituição, como foi o caso da normalista Augusta Rodrigues que, segundo consta no relatório municipal, fora formada pela Escola Normal de Paris.

De acordo com os registros obtidos nos relatórios municipais referentes às exposições anuais dos trabalhos confeccionados pelas órfãs, uma das mais importantes aconteceu no ano de 1908. Na oportunidade, diante de um grande público, foi celebrada por João Pedro de Figueiredo, padre e capelão da instituição, o santo sacrifício da missa, acompanhado a órgão por uma religiosa e a canto por quinze educandas, sendo entoadas as peças musicais Kyries, Sanctus, Agnus-Dei e Inviolata:

A essa cerimonia assistiram, além de innumeras senhoras, varios cavalheiros, senhoritas e a corporação de alumnas do instituto trajando alegres vestidos de fustão branco com faixa de setim azul. Ao fim da missa fóram convidados os presentes a assistirem a inauguração dos trabalhos, o que se verificou no amplo salão ao flanco esquerdo do edifício. (Belém, 1909, p. 293)

A festa seguiu com várias homenagens, com destaque para a leitura de um texto em agradecimento ao benfeitor da instituição, o intendente municipal de Belém, Antonio Lemos. Diz o texto:

Exm. Sr. Senador, minhas Senhoras e meus Senhores, - Sem orgulho, mas com imemnso gaudio, venho em nome das minhas collegas cumprimentar ao nosso ilustre bemfeitor e a todos aquelles que nos concederam a honra de abrilhantar e engrandecer a inauguração da humilde exposição de trabalhos desta humanitaria casa onde, Deus bemdito, se nos dá uma formação util, sã ao espirito, ao coração e aos sentimentos". Pedindo vênia a tão distinctos personagens para protestarIhes todo o reconhecimento das educandas deste collegio, mais uma vez, pelo jubilo da nossa gratidão immensa, digne-se o magnanimo protetor do Orfanato, o Exm. Sr. Senador, receber a espontanea e profunda manifestação do respeitoso e vivo sentimento e filial reconhecimento que a S. Exc. devotamos. (Belém, 1909, p. 293) 
Após serem proferidas essas palavras pela interna Antonia Miranda, foi cantado, por todas as demais educandas, o Hymno ao trabalho com o acompanhamento de piano. Ao final da execução do hino, foi liberada a visita do público à exposição, onde estavam à venda os diversos trabalhos de agulha, matiz, retróz, pincel e de flores.

Desta vez as peças foram organizadas de acordo com a produção das educandas, levando em consideração a capacidade física e intelectual de cada aluna. Estas orientações revelam a forma como os trabalhos eram desenvolvidos no interior da instituição e indicam alguns parâmetros relacionados à aprendizagem e ao desenvolvimento dos estudos, uma vez que os trabalhos manuais se configuravam como disciplina curricular, não só para as educandas do Orphanato, mas também para alunas do sexo feminino das demais escolas do Município e do Estado (Belém, 1909).

Quadro 2

Algumas peças produzidas pelas órfãs de acordo com sua capacidade nas aulas manuais e de prendas.

\begin{tabular}{|c|c|}
\hline Trabalhos das alumnas maiores & Trabalhos das alumnas menores \\
\hline $\begin{array}{l}\text { Colchas, lençóis, fronhas, toalhas, ditos, } \\
\text { guardanapos, porta-talheres, bolsas, } \\
\text { camisões, tapetes, camisas, vestidos } \\
\text { bordados à mão com utilização de linho, seda, } \\
\text { renda, fios de ouro. Além de outras peças de } \\
\text { crochê, pintura, flores artificiais e uma } \\
\text { variedade de trabalhos de costura. }\end{array}$ & $\begin{array}{l}\text { Alfineteiras, limpa-pernas, porta-cartões, } \\
\text { tapetes para tinteiros, cestinhas de crochê, } \\
\text { porta-relógios, bolsinhas de pelúcia, caixinhas } \\
\text { de papel de arroz, porta-copos de crochê, } \\
\text { almofadinhas para toalete. }\end{array}$ \\
\hline
\end{tabular}

Fonte: Elaborado a partir Relatório da Intendência Municipal de Belém, 1909.

Todo o recurso resultante da venda dos produtos das exposições era destinado à compra de novos materiais para a aprendizagem das órfãs nos trabalhos manuais. Em geral, as exposições aconteciam por algumas semanas, até que todas as peças fossem vendidas.

A aprendizagem doméstica e de trabalhos manuais aplicados às órfãs do Orphanato Municipal significaram mais que uma simples prática pedagógica determinada pelos programas de ensino, elas foram uma das formas de sobrevivência imposta às educandas e que se alinhavam às representações da mulher no contexto social da época.

\section{Considerações finais}

O estudo revelou que diante do cenário vivido a partir do final do século 19 e da primeira década do século 20 , a caridade e o poder público municipal de Belém não se furtaram em amparar as órfãs desvalidas, garantindo-lhes um mínimo de cuidado e instrução, mesmo que o maior propósito, pelo menos nos anos iniciais da República, fosse dar um destino adequado a esse contingente populacional e, em consequência disso, garantir a tranquilidade dos moradores, a moralidade e a ordem pública.

Não se pode negar a importância do governo Antonio Lemos para a história da cidade e, sobretudo, para o Orphanato Municipal. Durante sua administração (18971911), a cidade se projetou no cenário nacional a partir das grandes reformas por que 
passou em todos os setores públicos. Em vista disso, qualquer estudo que venha a ser feito acerca do Orphanato Municipal, necessariamente, deverá destacar o período de sua administração e sua importância para os anos seguintes da constituição da instituição.

As evidências apontaram que mesmo partindo da relevância de uma formação ainda que rudimentar em primeiras letras para as órfãs, não houve, por parte do Executivo Municipal de Belém, a preocupação em detalhar esses procedimentos nos regulamentos. Essa situação foi constatada mediante cruzamento dos documentos, nos quais se previa que todos os encaminhamentos pedagógicos das escolas municipais, assim como das classes que funcionavam no internato, seriam regidos pelos regulamentos estaduais vigentes no período demarcado neste estudo.

Assim, questões referentes aos programas e conteúdos, métodos de ensino, processos avaliativos, entre outras, eram aplicadas segundo orientação das leis estaduais e municipais e, no que diz respeito ao mobiliário e aos objetos escolares, o Orphanato Municipal se destacava por ter como finalidade a necessidade de uma formação assentada na experiência prática, focada nas aprendizagens manuais e domésticas.

Essas seriam as principais matrizes de formação no interior da instituição que indicavam o lugar que a educanda órfã deveria assumir na sociedade, que se pautava em preparar mães de famílias, com fortes inclinações religiosas e habilitadas nas prendas e no trabalho doméstico.

\section{Referências}

A ESCOLA - REVISTA OFFICIAL DE ENSINO. Belém, anno I, volume II, out. de 1900 a mar. de 1901.

CONSELHO MUNICIPAL BELÉM. Lei n. 283, de 27 de dezembro de 1900. Autoriza o Intendente a receber da Associação Protectora dos Orphãos o instituto de caridade denominado "Orphelinato Paraense". Leis e Resoluções Municipaes codificadas na administração Municipal do Senador Antonio José de Lemos. Belém: Typographia de Tavares Cardoso e Cia., 1901.

BELÉM. Relatório apresentado ao Conselho Municipal de Belém na sessão de 15 de novembro de 1902, referente aos anos de 1897-1902, pelo Intendente Municipal Senador Antonio José de Lemos. Belém: Typographia de Alfredo Augusto Silva, 1902.

BELÉM. Relatório apresentado ao Conselho Municipal de Belém na sessão de 15 de novembro de 1904, referente ao ano de 1903, pelo Intendente Municipal Senador Antonio José de Lemos. Belém: Typographia de Alfredo Augusto Silva, 1904.

BELÉM. Relatório apresentado ao Conselho Municipal de Belém na sessão de 15 de novembro de 1905, referente ao ano de 1904, pelo Intendente Municipal Senador Antonio José de Lemos. Belém: Archivo da Intendência Municipal, 1905.

BELÉM, O Município de./Relatório apresentado ao Conselho Municipal de Belém, referente ao ano de 1906, pelo Intendente Municipal Senador Antonio José de Lemos. $5^{\circ}$ volume. Belém: Archivo da Intendência Municipal, 1907.

BELÉM. Relatório apresentado ao Conselho Municipal de Belém, referente ao ano de 1908, pelo Intendente Municipal Senador Antonio José de Lemos. $7^{\circ}$ volume. Belém: Archivo da Intendência Municipal, 1909. 
GONÇALVES NETO, Wenceslau. O município e a educação em Minas Gerais: a implementação da instrução pública no início do período republicano. In: GONÇALVES NETO, Wenceslau; CARVALHO, Carlos Henrique de (orgs.). O município e a educação no Brasil: Minas Gerais na primeira república. Campinas: Alínea, 2012, p. 23-42.

GONDRA, José Gonçalves; SCHUELER, Alessandra. Educação, poder e sociedade no império brasileiro. São Paulo: Cortez, 2008.

GONDRA, José Gonçalves. Cronologias da vida e formas de escola. In: BENCOSTTA, Marcus Levy. (org.). Culturas escolares, saberes e práticas educativas: itinerários históricos. São Paulo: Cortez, 2007, p. 212-236.

LIVRO DE MATRÍCULADO - Orphanato Municipal Antonio Lemos. Belém, 1893.

LOBO, Lilia Ferreira. Os infames da história: pobres, escravos e deficientes no Brasil. Rio de Janeiro: Lamparina, 2008.

MACHADO, Maria Cristina Gomes. O decreto de Leôncio de Carvalho e os pareceres de Rui Barbosa em debate: a criação da escola para o povo no Brasil no século 19. In: STEPHANOU, Maria; BASTOS, Helena C (orgs.). Histórias e memórias da educação no Brasil. Petrópolis: Vozes, 2005.

NAGLE, Jorge. Educação e sociedade na primeira república. São Paulo: EPU, 1976.

NASCIMENTO, Terezinha A. Q. Ribeiro do. Pedagogia liberal modernizadora: Rui Barbosa e os fundamentos da educação republicana. Campinas: Autores Associados, 1997.

PARÁ. Album de Belém do. Paris: Imprimé par Phillippe Renouard, 1902.

PARÁ. A Instrucção Publica no Estado do Pará em 1890. Relatório apresentado ao Exmo. Governador do Estado Dr. Justo Leite Chermont, pelo Director Geral da Instrução Pública José Veríssimo. Belém: Typographia de Tavares Cardoso e Comp., 1891.

PARÁ. Decreto n. 1.689, de 28 de abril de 1910. Dá nova organização ao Ensino Primario do Estado. Belém: Imprensa Official do Estado do Pará, 1910.

RIZZINI, Irene. O século perdido: raízes históricas das políticas públicas para a infância no Brasil. São Paulo: Cortez, 2008.

RIZZINI, Irene. Crianças e menores - do pátrio poder ao pátrio dever: um histórico da legislação para a infância no Brasil. In: RIZZINI, Irene; PILOTTI, Francisco (orgs.). A arte de governar crianças: a história das políticas sociais, da legislação e da assistência à infância no Brasil. São Paulo: Cortez, 2009, p. 97-151.

SARGES, Maria de Nazaré. Belém: riquezas produzindo a belle-époque (1870-1912). Belém: Paka-Tatu, 2002 a.

SARGES, Maria de Nazaré. Memórias do velho intendente (1869-1973). Belém: PakaTatu, 2002b.

SOUZA, Rosa Fátima de. História da cultura material escolar: um balanço inicial. In: BENCOSTTA, Marcus Levy. (org.). Culturas escolares, saberes e práticas educativas: itinerários históricos. São Paulo: Cortez, 2007, p. 163-189.

VEIGA, Cynthia Greive. História da educação. São Paulo: Ática, 2007.

VIDAL, Diana Gonçalves Vidal; GVIRTZ, Silvina. O ensino da escrita e conformação da modernidade escolar: Brasil e Argentina (1880-1940). Revista Brasileira de Educação. Caxambu, v. 8, 1998, p. 13-30. 
YAZBECK, Lola. A criação de escolas e o preparo do professor (1892-1906). In: GONÇALVES NETO, Wenceslau; CARVALHO, Carlos Henrique de (orgs.). O município e a educação no Brasil: Minas Gerais na primeira república. Campinas: Alínea, 2012, p. 7387.

ANTONIO VALDIR MONTEIRO DUARTE é doutor em Educação, na linha de História e Historiografia da Educação, pela Universidade Federal de Uberlândia/MG, professor vinculado à Secretaria de Estado de Educação do Pará e à Secretaria Municipal de Educação de Belém.

Endereço: Rua Hélio Pinheiro de Almeida, 300/402, bloco 1 - 66635-040 - Belém PA - Brasil.

E-mail: montearte13@yahoo.com.br.

Recebido em 8 de novembro de 2013.

Aceito em 14 de abril de 2014. 